\title{
OPTICAL AND DIELECTRIC PROPERTIES OF THE COBALT DOPED TiO NANOPARTICLES
}

\author{
M. H. MANGROLA ${ }^{\dagger}$ and V. G. JOSHI ${ }^{1}$ \\ ${ }^{\dagger}$ Faculty of Engineering Technology and Research, Department of Physics, Gujarat Technological University \\ Afwa-Isroli, Gujarat, India. \\ ${ }^{1}$ Department of Physics, Veer Narmad South Gujarat University, Surat, Gujarat, India. \\ mhmangrola@gmail.com ${ }^{\S}$ \\ B. H. PARMAR ${ }^{2}$, A. S. PILLAI ${ }^{2 a}$ \\ ${ }^{2}$ Department of Physics, Veer Narmad South Gujarat University, Surat, Gujarat, India. \\ ${ }^{2 a}$ Department of Physics, B. P. Baria Science Institute, Navsari, Gujarat, India
}

\begin{abstract}
Cobalt doped Titanium Dioxide $\left(\mathrm{TiO}_{2}\right)$ were synthesized by a standard solid-state reaction method. The dielectric constant and loss have been measured as a function of frequency $(100 \mathrm{~Hz}-$ $1 \mathrm{KHz}$ ) and temperature $\left(50^{\circ} \mathrm{C}\right.$ to $\left.300^{\circ} \mathrm{C}\right)$. Similar behavior is observed between dielectric constant and dielectric loss. Both dielectric constant and dielectric loss are found to decrease with increasing frequency. Photoluminescence (PL) spectra were taken at different excitation wavelength. PL emission spectra shows a broad spectra in the range $400 \mathrm{~nm}$ to $500 \mathrm{~nm}$.
\end{abstract}

Keywords: $\mathrm{TiO}_{2}$ (Anatase phase), Co doped $\mathrm{TiO}_{2}$, PL, Dielectric.

\section{Introduction}

Titanium dioxide $\left(\mathrm{TiO}_{2}\right)$ nanomaterials are used in a wide range of application such as photocatalysis, separations, sensor devices, paints and dye-sensitized solar cell [1-3]. Dielectric property of prepared anatase and rutile $\mathrm{TiO}_{2}$ shows that the main difference in the dielectric constant value is defined by oxygen content in $\mathrm{TiO}_{2-\mathrm{X}}$. It is also reported that at high temperature, phase transitions occur in anatase $\mathrm{TiO}_{2}$ thin films [4]. Mustafa Okutan has reported on alternating current (AC) conductivity and dielectric properties of the Co-doped $\mathrm{TiO}_{2}$ (rutile). They had observed an increase in dielectric constant with temperature which is due to polarization related to the thermal motion of electrons [5]. The $\mathrm{TiO}_{2}$ nanowires can emit blue-green light peaked at $487 \mathrm{~nm}$ under excitation at 413 $\mathrm{nm}$. The $\mathrm{TiO}_{2}$ nanowires have a very strong PL band at blue-green wavelength range. The nanowires have many potential applications in photocatalysts and photoelectronics [6].

\footnotetext{
${ }^{\dagger}$ M. H. Mangrola and V. G. Joshi

${ }^{\dagger}$ Faculty of Engineering Technology and Research, Department of Physics, Gujarat Technological University and ${ }^{1}$ Department of Physics, Veer Narmad South Gujarat University, Surat.

${ }^{\ddagger}$ Afwa-Isroli, Dist. Surat, State: Gujaart, INDIA.

${ }^{\S}$ mhmangrola@gmail.com
} 


\section{Experimental Detail}

The two samples $3 \% \& 5 \%$ Co-doped $\mathrm{TiO}_{2}$ has been prepared in this work. Precursor $\mathrm{TiO}_{2}$ were calcinate at $450^{\circ} \mathrm{C}$ for 2 hours in silica crucible in air atmosphere. The $3 \% \&$ $5 \%$ Co-doped $\mathrm{TiO}_{2}$ was mixed and grind by agate mortar with pestle for one hours before each thermal treatment. The powder was calcined at $450^{\circ} \mathrm{C}$ for 10 hours in silica crucible in air atmosphere. The process was repeated several times to ensure homogeneous state with single phase powder.

\section{Result and Discussion}

\subsection{Dielectric Analysis}

Co-doped $\mathrm{TiO}_{2}$ shows a linear dielectric behavior with increasing the doping concentration. Figure 1a, shows that initially in the range of 50 to $100^{\circ} \mathrm{C}$ the dielectric constant decreases, but after that, it increases in the temperature range from $100^{\circ} \mathrm{C}$ to $250^{\circ} \mathrm{C}$. At higher temperature a fall in dielectric constant is observed. Because cobalt is a conducting transition metal, a decrease in dielectric constant is observed with increasing Co-concentration.

The dielectric behavior with variation in temperature is due to the random vibration of ions and electrons, which becomes less susceptible to orientation in the field direction. Cobalt doped $\mathrm{TiO}_{2}$ shows high dielectric loss at low temperature and at high temperature dielectric loss is low.

Fig. 1b, shows the change in dielectric loss with temperature for the prepared samples. It is seen that pure $\mathrm{TiO}_{2}$ shows greater dielectric loss and Co-doped $\mathrm{TiO}_{2}$ shows comparatively low dielectric loss.

Fig. 1c and fig. 1d shows the variation of the dielectric constant and dielectric loss of the $\mathrm{TiO}_{2}, 3 \%$ Co doped $\mathrm{TiO}_{2}$ and $5 \%$ Co doped $\mathrm{TiO}_{2}$ with frequency at $50^{\circ} \mathrm{C}$ temperature. The dielectric constant of all samples decreases almost exponentially with operating frequency. The high dielectric constant arises from the very strong local internal electric field in $\mathrm{TiO}_{2}$, which is caused by the external applied electric field, causing strong electronic polarization and ionic polarization. At higher frequency both dielectric constant and dielectric loss remain constant means in relaxation behavior, or in other words the frequency increases dipoles start to leg behind the field and dielectric constant slightly decreases and at very high frequency dipoles are not able to follow the field for large. The variation in the dielectric behavior in the sample is attributed to the interfacial polarization.

\subsection{Photoluminescence Analysis}

Photoluminescence study shows that the PL intensity of $\mathrm{TiO}_{2}$ at room temperature is significantly higher that of Co-doped $\mathrm{TiO}_{2}$ in the range of $375-525 \mathrm{~nm}$. The PL intensity gradually decreases with higher doping of cobalt. It is also observed that the main PL peak of $\mathrm{TiO}_{2}$ occurs at $450.84 \mathrm{~nm}$ while those of cobalt doped $\mathrm{TiO}_{2}$ turns up at 
$450.93 \mathrm{~nm}$ for $3 \%$ and $451.59 \mathrm{~nm}$ for $5 \%$, respectively. These results indicate that the position of PL peaks is gradually shifted towards the Blue-red direction with the increase of Co-ion dosage from $3 \%$ to 5\%. The doping is an effective approach to adjust the Fermi energy level for semiconductors. The relation between electron conduction and the Fermi level is given by S. M. Sze. [8].

The PL emission mainly results from the recombination of excited elements and holes, the lower PL intensity indicated the less recombination of electron hole pair and higher separation efficiency. The PL behavior of $\mathrm{TiO}_{2}$ is also highly dependent on the grain size [9]. In the present work, we observe many tiny peaks which is due to the energies levels introduced by lattice defects.

\section{Conclusion}

Cobalt doped $\mathrm{TiO}_{2}$ shows a more linear behaviour and low dielectric loss as compared with pure $\mathrm{TiO}_{2}$ on increasing the operating frequency. PL study indicates that on increasing Co concentration the PL peak shift.

\section{Illustrations and Photographs}
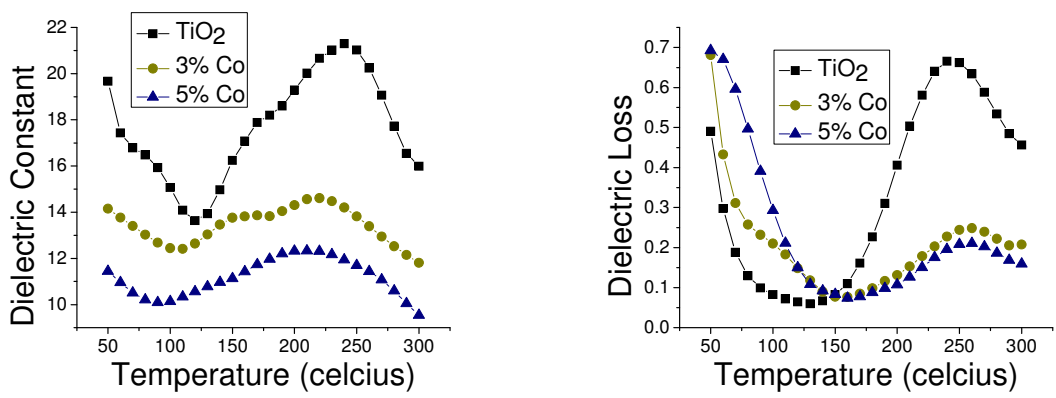

Fig. 1a \& 1b. Shows Dielectric constant Vs Temperature and Dielectric Loss Vs Temperature $\left(50^{\circ} \mathrm{C}\right.$ to $\left.300^{\circ} \mathrm{C}\right)$ with $10 \mathrm{kHz}$ frequency.
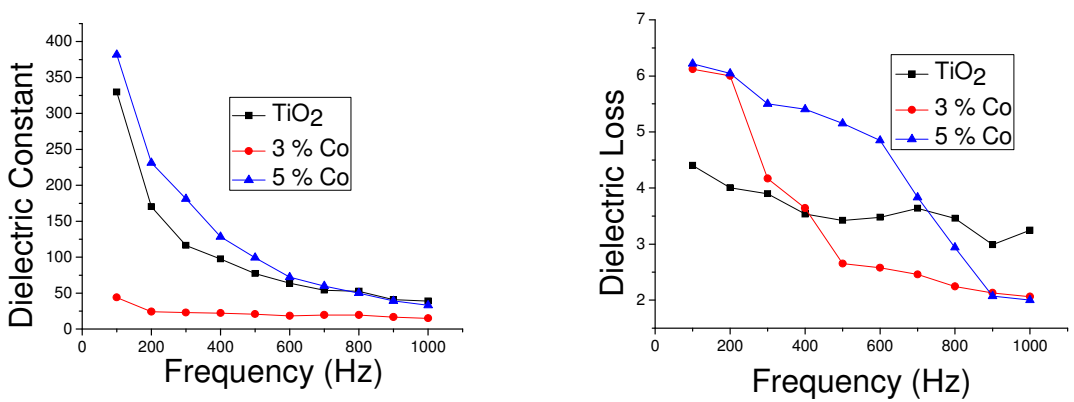

Fig. 1c \& 1d. shows Dielectric constant Vs Frequency and Dielectric loss Vs Frequency $\left(\right.$ at $50^{\circ} \mathrm{C}$ ) of the samples. 

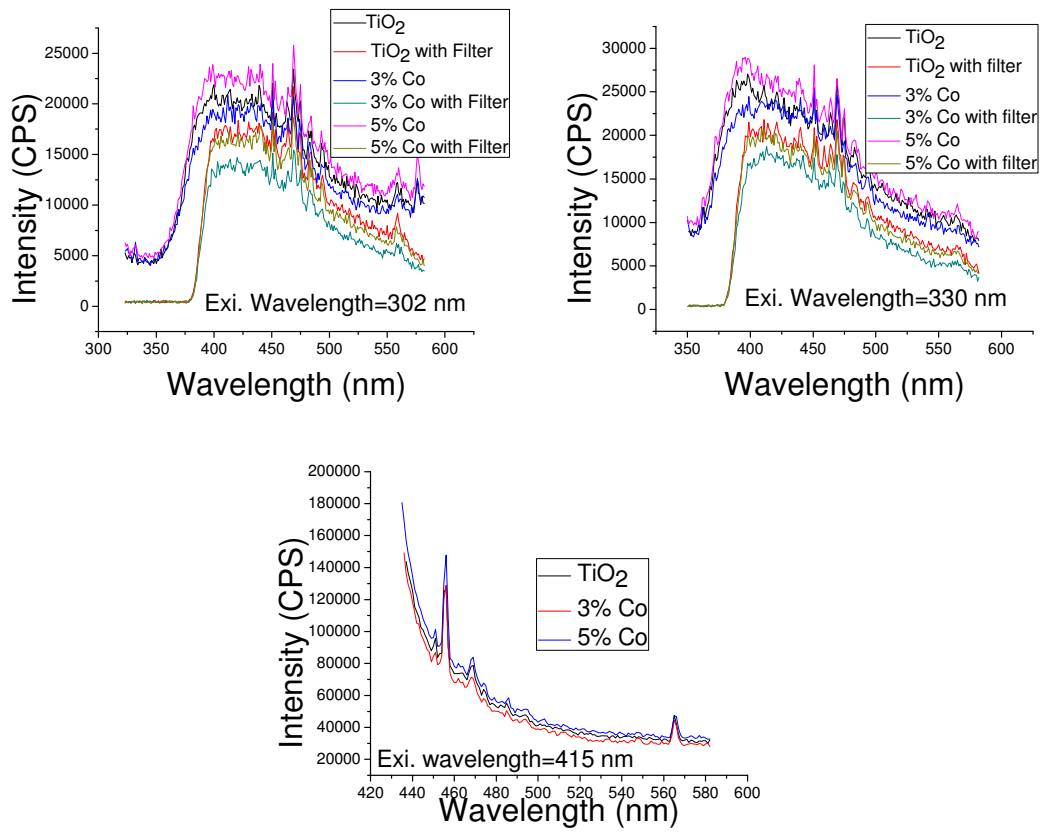

Fig. 2a,2b and 2c. Shows Photoluminescence Spectra of the sample at the different excitation wavelength.

\section{Acknowledgments}

Rajiv Gandhi UGC fellowship to one of the authors (M. H. Mangrola) is fully acknowledged. The authors also wish to thank UGC DAE CSR Indore, Dr. B. S. Chakrabarty (Applied Physics Department, M. S. University of Baroda), Dr. Vandana N Rao (Metallurgy \& Material Science Department, M. S. University of Baroda) and Dr. M. Roy (M. L. Sukhadiya University, Udaipur) for their support and valuable suggestions.

\section{References}

1. A Hagfeldt and M Gratzel, Chem. Rev. (1995) 9549.

2. M. R. Hoffmann, S. T. Martin, W. Choi and D. W. Bahnemann, Chem Rev. (1995) 9569.

3. X. Chen and S. S. Mao Chem. Rev. (2007) 1072891.

4. Valentin Bessergenev, Materials Research Bulletin (2009) 44 1722-1728.

5. M. Okutan, E. Basaran, H. I. Bakan, F. Yakuphanoglu, Physica B (2005) 364 300-305.

6. L. Kumaresan, M. Mahalakshmi, M. palanichamy and V. Murugesan, Ind. Eng. Chem. Res. (2010) 49 1480-1485.

7. Mustafa Okutan, Engin Basaran, Halil I. Bakan, Fahrettin Yakuphanoglu., Physica B 364 (2005) 300-305.

8. S. M. Sze, Physics of semiconductor devices, (1981) p 84.

9. W. F. Zhang, M. S. Zhang, Z. Yin, Q. Chen, Appl. Phys. B 70, 261-265, (2007).

10. Y. Toyozawa, in relaxation of elementary Excitation (Edited by R. Kubo \& E. Hanamura), p. 3 Springer-Verlag, New York (1980) 